\title{
Microorganisms that Manipulate Complex Animal Behaviours by Affecting the Host's Nervous System
}

\author{
Chelsie E. Rohrscheib · Jeremy C. Brownlie
}

Received: 25 March 2013/Revised: 24 July 2013 / Accepted: 26 July 2013 / Published online: 24 August 2013

(c) Springer International Publishing AG 2013

\begin{abstract}
Symbioses occur in all higher organisms and have evolved to play an important role in host biology. Researchers have been studying the effects that microbial symbionts have on host biology for decades but have only recently begun to examine how they influence the brain and behaviour. This review aims to provide several examples of different symbionts that have demonstrated the ability to manipulate the behaviour of their hosts and described the current evidence for the molecular mechanisms used by the symbiont to alter the host's nervous system and modify behaviour to illustrate the common points of interaction between symbiont and host.
\end{abstract}

Keywords Symbiont - Symbiosis - Behaviour nervous system - Wolbachia Gut bacteria

C. E. Rohrscheib $(\bowtie) \cdot$ J. C. Brownlie

School of Biomolecular and Physical Science,

Griffith University, Nathan, QLD 4111, Australia

e-mail: c.rohrscheib@griffith.edu.au

\section{E. Rohrscheib}

Eskitis Institute of Cell and Molecular Therapies, Griffith University, Nathan, QLD 4111, Australia

\section{E. Rohrscheib}

Queensland Brain Institute, University of Queensland,

St. Lucia, QLD 4067, Australia

\section{J. C. Brownlie}

Environmental Futures Centre, Griffith University,

Nathan, QLD 4111, Australia

e-mail: j.brownlie@griffith.edu.au

\section{Introduction}

Symbioses occur in all higher organisms and have evolved to play an important role in host biology [41, 68]. Symbionts helped to establish and diversify eukaryotes and continue to be an important driving force in evolution by inducing diverse physiological, morphological and developmental modifications in the species involved $[5,30]$. The word "symbiosis" was first coined by the German scientist Heinrich Anton de Bary in his monograph "Die Erscheinung der Symbiose" [3] while studying the formation of lichens, composite organisms which are the result of an association between a fungus and an alga. He described the phenomenon as "the living together of differently named organisms". We now understand that a symbiosis is the close and prolonged relationship between two or more biological organisms of a different species; the symbiont is dependent upon the host for survival. The impact the symbiont has on it host varies from detrimental (parasitism), neutral (commensal) or beneficial (mutualistic) [24, 25]; however, many symbiotic relationships do not fit neatly into a discrete category and can deviate between these states under different environmental conditions or through time $[12,40]$. Much of the symbiosis field has focused on understanding the mechanisms by which parasitic symbionts induce disease or how mutualists improve or maintain host fitness. Increasingly, symbionts have been observed to influence other host fitness traits, including complex behaviours.

Behaviour is a voluntary or involuntary response of an organism in relation to its environment [56], which is controlled by the coordinated actions of neuronal cells within the brain $[27,32]$. The long-held dogma of behavioural research is that animal behaviour is determined by the complex interplay between genetics and the surrounding environment 
[57]. An increasing body of evidence that shows microbes significantly influence animal behaviour [2, 51, 54] suggests microbes are a third determinant of behaviour (Forsythe and Kunze 2012). These observations are consistent with evolutionary theory predicting that organisms can evolve to manipulate their host to increase their fitness, a process referred to as the "extended phenotype" [20, 44]. Genetic mutations that arise within symbionts that enable them to manipulate their host's behaviour, and in turn increase their survival or that of their offspring, will be selected for.

While numerous behaviour-modifying microbes have been observed, understanding the mechanisms by which microbes manipulate behaviour is a challenging problem for biologists. Here we provide several examples of different symbionts that have demonstrated the ability to manipulate the behaviour of their animal hosts by altering the host's nervous system. We describe the behaviours elicited and discuss the current evidence for the molecular mechanisms used. Finally, we outline potential directions for future research in this emerging cross-disciplinary field.

Microbes that Manipulate Neural Protein Synthesis

\section{Spinochordodes tellinii}

The parasite Spinochordodes tellinii is a nematode hairworm that infects grasshoppers and crickets to complete the final stage of its life cycle. The parasite infects its host either by (1) direct infection with larvae or free encysted (in the environment) larvae or by (2) indirect infection by larvae encysted within an intermediate host that is consumed by a definitive host [34]. Spinochordodes tellinii continues developing within the host until it reaches the point of its aquatic adult stage. The adult worm lives and reproduces in the water and therefore must be deposited into a water source to finalise its life cycle. It does this by manipulating host behaviour by causing the host to wander into atypical habitats that may contain a water source and causing it to drown by entering the water. The adult worms then emerge from the host where they seek out other adults for sexual reproduction $[66,76]$. These changes are highly specific, occurring at night-time, and are completely novel for the grasshopper, which naturally avoids drowning.

To understand how $S$. tellinii manipulates host behaviour, proteomics were used to compare the central nervous system and brains of infected and uninfected grasshoppers [10]. Three broad categories of proteins were shown to be influenced by $S$. tellinii (Table 1). The first category was proteins that play a direct role in the development of the brain, including proteins from the Wnt family and one family of proteins linked to the regulation of apoptosis (caspase recruitment domains, CARD). Parasites often regulate apoptotic processes to avoid the host immune system, and in doing so, they indirectly influence the development of the host central nervous system [10]. The second category was neural peptides that control water-seeking, hI and hK, or geotactic behaviour (the oriented movement of an organism in response to gravity), while the third category was proteins that regulated neurotransmitter release. It was concluded that S. tellinii induces changes to host biochemical interactions, through a combination of indirect and direct mechanisms, which in turn directly affect the functioning of the host's CNS and ultimately behaviour [10].

\section{Wolbachia pipientis}

Wolbachia pipientis, a gram-negative alpha-proteobacteria, is one of the most common intracellular bacterial symbionts on earth infecting numerous filarial nematodes, arachnids and at least $40 \%$ of all insect species [38, 45, 85, 88]. Wolbachia are maternally transmitted and are best known for their ability to manipulate host sex determination or reproductive systems to promote their transmission; recent studies have also shown that Wolbachia can manipulate insect behaviour as well.

Most Wolbachia behavioural studies to date have focused on two related fly species, Drosophila melanogaster and D. simulans. In both species, Wolbachia infection is correlated with higher mating frequencies in males when compared to uninfected flies [17]. Wolbachia has also been shown to influence locomotion behaviour in infected Drosophila in response to olfactory cues, though the effects are influenced by host background and environmental conditions [15, 61, 62]. Under controlled laboratory conditions D. melanogaster infected by Wolbachia showed reduced olfactory-cued performance compared to Wolbachia-free flies [61], while field studies showed an increased olfactory response compared to their Wolbachia-free counter parts [15]. Though conflicting, both studies demonstrate that Wolbachia do influence D. melanogaster olfactory-cued performance and that the nature of the modification is contextual.

Wolbachia-infected D. simulans display an increased olfactory-cued performance and were more sensitive to odorants in a T-maze than the uninfected controls under standard laboratory conditions [61, 62]. Olfactory response was influenced by Wolbachia density, where higher Wolbachia density correlated with a faster navigation times to the food source or odorants. Quantitative RT-PCR showed that the transcript of an important odorant receptor gene or83b (Table 1), which is expressed in approximately twothirds of all olfactory receptor neurons [46, 79], was significantly higher in flies with a fast olfactory response [62]. These results suggest Wolbachia increases olfactory response by regulating the expression of olfaction-receptor genes in D. simulans. As olfactory processes are known to 
Table 1 Behaviour-modifying microbes and known mechanism

\begin{tabular}{|c|c|c|c|}
\hline Symbiont & Behavioural change & Mechanism & Host \\
\hline Spinochordodes tellinii [9] & $\begin{array}{l}\text { Geotactic and water-seeking } \\
\text { behaviour }\end{array}$ & Alters neural proteins synthesis & $\begin{array}{l}\text { Grasshoppers, } \\
\text { crickets }\end{array}$ \\
\hline Euhaplorchis californiensis [72] & $\begin{array}{l}\text { Impulse-driven, active and } \\
\text { aggressive behaviour }\end{array}$ & $\begin{array}{l}\text { Alters monoamine neurotransmitter } \\
\text { levels and signalling }\end{array}$ & Killifish \\
\hline Toxoplasma gondii [29] & $\begin{array}{l}\text { Predator evasion, fear and anxiety } \\
\text { behaviour }\end{array}$ & $\begin{array}{l}\text { Alters dopamine neurotransmitter } \\
\text { levels and signalling }\end{array}$ & Mice, rats \\
\hline Wolbachia pipientis [62] & $\begin{array}{l}\text { Olfactory-cued locomotion } \\
\text { behaviour }\end{array}$ & $\begin{array}{l}\text { Manipulation of gene expression } \\
\text { and neural development }\end{array}$ & Fruit flies \\
\hline Gut bacteria in mice $[19,36]$ & Anxiety and locomotion behaviour & $\begin{array}{l}\text { Manipulation of gene expression } \\
\text { and neural development }\end{array}$ & Mice \\
\hline $\begin{array}{l}\text { Gut bacteria in Drosophila } \\
{[69,70]}\end{array}$ & Mate preference behaviour & Manipulation of sex pheromones & Fruit flies \\
\hline$H z N V-2[13]$ & Mate calling behaviour & Manipulation of sex pheromones & Moths \\
\hline
\end{tabular}

influence learning, memory and attention, Wolbachia may inadvertently modify these complex behaviours as well.

Microbes that Manipulate Neurotransmitter Levels and Signalling

\section{Euhaplorchis californiensis}

Euhaplorchis californiensis are trematodes that live in the gut of Californian shorebirds. The parasite produces eggs in the gut of the bird that are then released into the local waterways following defecation. The faeces are eaten by horn snails allowing the eggs to hatch into larvae within the snail. Interestingly, the parasite can then live within the snail for several generations, inducing sterility. The larvae mature into the cercariae stage, the free-swimming phase in which a parasitic fluke passes from an intermediate host to another, and navigate into marshes, the natural habitat of the killifish, Fundulus parvipinnis. The larvae attach themselves to the gills of the killifish and make their way along a nerve into the brain cavity. Once fully established in the brain, the fish develop thousands of cysts in the brain yet still mature at rates comparable to the uninfected fish. A dramatic behavioural change occurs when the parasite reaches high density in the hippocampus, in which the fish move to the surface and swim in circles in a flailing motion, exposing their silver undersides to the surface, attracting seabirds. The birds catch and consume the fish, allowing the completion of E. californiensis life cycle [50, 71]. A recent study by Shaw and Overli [72] suggests a mechanism for how the trematode alters behaviour in the killifish (Table 1).

Fish infected with E. californiensis were found to have altered levels and signalling of monoamine neurotransmitters, serotonin and dopamine, which control locomotion and social behaviour. A direct correlation was found between high parasitic density in the hippocampus, an increase in dopaminergic activity and a decrease in serotonergic activity in the hippocampus. Additionally, low parasitic density in the raphae nuclei, an area within the brain stem responsible for anxiety and aggression, was associated with the inhibition of normally occurring, stress-induced elevation of serotonergic metabolism [75]. This suggests that by altering serotonin and dopamine signalling in the fish, E. californiensis may induce changes to impulse-driven, active and aggressive behaviour in its hosts [72].

\section{Toxoplasma gondii}

One of the most wildly studied parasites that infect the mammalian nervous system is the protozoan $T$. gondii. Toxoplasma gondii can infect most warm-blooded animals, including humans; however, its primary host is the domesticated cat. Animals can be infected by accidental ingestion of faeces from an infected cat, ingestion of contaminated meat or by transmission from mother to foetus. It is believed that up to a third of the human population is infected with T. gondii [58, 78].

Several dramatic behavioural changes that do not occur in the primary feline host are noted in infected mice and rats, which are the intermediate hosts for $T$. gondii. For instance, the protozoan has the ability to reduce the rodent's fear of cats and make the rats become attracted to cat urine [7]. Further studies in infected rodents show prolonged reaction time to stimuli [42], heightened preference for novel stimuli $[6,82,83]$, reduced ability to learn $[39,86]$ and increased general activity and locomotion [35]. Interestingly, infected rats also have a higher capture rate in traps [83]. It is thought that these changes in behaviour reduce the rodent's ability to evade predators 
and make it easier for felines to find, capture and eat the infected prey, allowing the parasite to enter the cat and complete its life cycle.

Chronic infection in rodents begins when parasites enter the brain, where hundreds to thousands of these parasites group together forming cysts, known as bradyzoites [21]. Bioluminescence imaging of the brain of rats infected with $T$. gondii found the number of cysts, and associated inflammation, was highest in the amygdala and hippocampal regions of the mouse brain, areas that control anxiety [8, 37, 80]. Having established high infection densities in these regions, $T$. gondii then increases the production of the neurotransmitter dopamine by $14 \%[16,73,74]$. The genome of $T$. gondii was found to contain two genes encoding tyrosine hydroxylase that in turn produces dopamine (Table 1). These enzymes displayed similar kinetic properties to metazoan tyrosine hydroxylases; intriguingly one of these enzymes was only induced during formation of the cysts within the rat brain [29]. Thus, by producing two enzymes capable of converting L-Tyrosine to L-Dopa [47], $T$. gondii are able to increase dopamine biosynthesis in the host. The effects of elevated dopamine can be ameliorated and normal behaviour restored using dopamine reuptake inhibitors, which reduce the amount of biologically active dopamine [73] or by blocking a major dopamine receptor D2 [84].

\section{Manipulation of Gene Expression and Neural Development}

\section{Gut Bacteria: Modulating Mammalian Brain Development, Function and Anxiety States}

Gut flora consists of microorganisms that live in the digestive tracts of vertebrate and invertebrate animals and occur mainly along mucosal surfaces [67]. The microbes within the gut are primarily made up of hundreds, possibly thousands, of bacterial species [63]; however, fungi and protozoa also make up a part of the gut flora, but little is known about their interaction with the host [31]. The relationship between gut bacteria and its host is largely mutualistic and the microorganisms perform a range of useful functions [4]. For instance, resident bacteria play an important role in host biology, supplying essential nutrients, metabolizing indigestible compounds and defending against colonisation of opportunistic pathogens [23, 52, 53]. A rapidly growing body of evidence indicates that there is an interaction between normal gut bacteria and the function of the central nervous system. This is highlighted by the relationship found between anxiety disorders and both inflammatory bowel disease and the functional bowel disorders $[18,81,87]$.
Most scientific research has examined how gut bacteria influences mammalian behaviour. Research by Heijtza et al. [36] used bacteria-free mice to demonstrate that gut microbiota impact motor control and anxiety. Bacteria-free (germ free, GF) mice were found to have altered behaviour that included anxiety when compared to mice missing specific bacterial species (specific pathogen free; SPF) or mice with complete gut microbe communities [36]. A second mouse study by Neufeld et al. [59] investigated basal behaviour of adult GF female mice compared to SPF mice. Locomotion did not differ between either groups. Mice were then tested in an elevated plus maze (EMP), which is used to test anxiety-like behaviours and consists of a plus-shaped apparatus with two open and two closed arms, with an open roof and elevated off the floor. Ordinarily, mice will avoid open spaces to minimise the risk of being seen by predators and spend far more time in the closed than in the open arms when placed in the EMP. GF mice spent more time exploring the open arm and decreased time exploring the closed arm compared to SPF, signifying decreased anxiety [59].

The observed reduction of anxiety correlated with altered expression of genes involved in second messenger pathways and synaptic long-term potentiation in hippocampal and amygdala brain regions that control motor control and anxiety-like behaviour (Table 1) [36]. GF mice exposed to gut microbiota early in life display similar neurological and behavioural features as the SPF mice, but both differed from the control mice. For instance, they both had reduced expression of $p s d-95$, a member of the membrane-associated guanylate kinase (MAGUK) family, which is involved in the maturation of excitatory synapses [26], suggesting that gut bacteria are crucial for neural development [36]. Furthermore, GF mice had altered expression in three genes $\left(B D N F, 5-H T_{1 A}\right.$ and $\left.N R 2 B\right)$ that influence brain function. Expression of brain-derived neurotrophic factor (BDNF), a protein that supports the survival of existing neurons and encourages the growth and differentiation of new neurons and synapses [1, 43], was increased, and the 5- $\mathrm{HT}_{1 \mathrm{~A}}$-serotonin receptor sub-type was decreased in the hippocampus and amygdala. The NR2B subunit of the NMDA receptor was also down-regulated in the amygdala. Interestingly, a previous study showed that deleting the BDNF receptor TrkB alters the way in which newly developed neurons integrate into hippocampal circuitry and lead to increased anxiety in mice [9]. These studies suggest that the absence of gut bacteria may affect neural development leading to altered behaviour. Bacteria colonise the gut in the days following birth, during a sensitive period of brain development, and may potentially induce changes in the expression [59].

More recent work has begun to investigate the link between specific species of gut bacteria and nervous 
system function. Bravo et al. [11] conducted a study examining how a common probiotic bacterium, Lactobacillus rhamnosus (JB- 1 ), affects emotional behaviour in the mouse. Wild-type mice were subjected to experiments that assess anxiety. These included the previously described EPM assay and stress-induced hyperthermia (SIH) test in which anxiety induced temperature elevation was measured before and after stress stimuli. Treatment of mice with large doses of $L$. rhamnosus ( $J B-1)$ resulted in reduced corticosterone (stress hormone) and anxiety- and depression-related behaviour compared to untreated mice [11]. A second study by Matthews and Jenks [55] investigated behavioural changes associated with Mycobacterium vaccae. Mice were fed live M. vaccae prior to being tested in an A Hebb-Williams style complex maze, a learning task that can reveal anxiety-related behaviours. Treated mice given $M$. vaccae had increased maze run times due to decreased anxiety behaviours within the maze.

Finally, specific bacteria species such as L. rhamnosus $(J B-1)$ were found to influence gamma-aminobutyric acid (GABA), the main CNS inhibitory neurotransmitter that is involved in regulating many neuronal processes. Alterations in central GABA receptor expression are implicated in the pathogenesis of anxiety and depression [19]. Treatment with $L$. rhamnosus $(J B-1)$ reduced GABAA $\alpha 2$ mRNA expression in the prefrontal cortex and amygdala, but increased GABAA $\alpha 2$ in the hippocampus. Interestingly, the neurochemical and behavioural effects were not shown in vagotomised mice, which points towards the vagus nerve as a major modulatory constitutive communication pathway between the gut flora and the brain. Together, these findings highlight the important role of bacteria in the bidirectional communication of the gut-brain axis and suggest that certain organisms may be useful in stressrelated psychiatric disorders such as anxiety and depression; however, further investigation needs to be conducted to determine how microorganisms communicate with the brain through the vagus nerve [11].

\section{Manipulation of Sex Pheromones}

\section{Gut Bacteria in Drosophila melanogaster}

In addition to manipulating neurotransmitters, some microbes have been shown to influence ligands of odorant neuron receptors; the most potent of these has been the manipulation of invertebrate sex pheromones, thereby influencing mating behaviour. Two recent studies by Sharon et al. [69, 70] found that gut bacteria influenced mating preference in Drosophila melanogaster. In the first study, two wild-type groups of flies were reared on separate food media (starch- or maltose-based food), both of which had the ability to influence gut flora due the unique bacterial populations within the media. Adult flies were given the choice to mate with one of two members of the opposite sex-one that had been reared on the same food, the other reared on the other food. There was a consistent preference, regardless of gender, to mate with flies raised on the same food medium. It was concluded adult flies had a stronger preference for mates with the same established gut flora profile [69, 70]. This hypothesis was extended when Sharon et al. [70] conducted a second study that manipulated the gut bacteria using antibiotics. Adult flies that had been reared on the same diet, and assumed to have similar gut flora, were then exposed to broad-spectrum antibiotics that disturbed the established gut microbiota. The removal of the gut bacteria also removed the preference for mates reared on the same food medium, suggesting that gut flora was responsible for the homogamic mating preference. Further experiments tested mate preference in germ-free flies that were subsequently reinfected by a single bacterial species, causing a significant increase in mating preference in flies with a newly established bacterial species with other flies that infected with the same bacteria, compared with antibiotic-treated controls. The second study also investigated possible mechanisms by which these changes to mate-choice might occur. Drosophila, as with many other animals, relies on visual and olfactory cues to determine attractiveness prior to mating. A number of sex pheromones are produced by Drosophila, and the exact composition and ratio of different cuticular hydrocarbons $(\mathrm{CH})$ are heavily selected upon. Analysis of the $\mathrm{CH}$ composition for antibiotic-treated flies found significant changes in at least four of the major $\mathrm{CHs}$ when compared to untreated insects (Table 1). In most cases, removal of gut bacteria correlated with a decrease in CHs. Thus, it appears that symbiotic gut bacteria influences mating behaviour by regulating the production of sex pheromones [69, 70].

\section{Viral: $H z N V-2$}

HzNV-2 is a rod shaped, enveloped, sexually transmitted virus that naturally infects the corn earworm moth species Helicoverpa zea. Viral replication occurs exclusively in the reproductive tissues of the moths and results in sterility [64]; however, some asymptomatic female remain fertile that act as carriers transmitting the virus vertically to their offspring via their ova [33]. HzNV-2 can also be horizontally transmitted during mating; to increase the rate at which this occurs, the virus modifies the infected female's mating behaviour. For instance, infected females produce more mating pheromones and attract more mates than virus-free females. Normally, mating pheromones influence female moths to demonstrate "calling" behaviour, which includes rapid wing vibrating and release of sex 
pheromones via the pheromone gland $[48,49,65]$. This behaviour results in the attraction of males that attempt to mate by clasping and holding the female's genitalia with their own [14]. After mating, pheromone titres decline and the female moths lose sexual interest due to the transfer of male-derived anti-calling factors, including a pheromonestatic peptide (PSP) [48]. Interestingly, HzNV-2 infected females in the presence of males demonstrate increased calling behaviour compared to the uninfected controls. Unlike the virus-free females, which discontinued calling after mating occurred, infected females continued calling even after male contact. Furthermore, HzNV-2 females attracted twice as many males on average as did control females [13]. While it is hypothesised that HzNV-2 alters sex pheromones thereby changing insect mating behaviour (Table 1), the exact molecular mechanisms by which these manipulations occur are poorly understood.

\section{Future Directions}

There are many symbionts known to modify animal behaviour. Understanding the mechanisms by which these microbes manipulate behaviour remains a challenging problem for biologists. Nevertheless, as demonstrated in this review, there are four conserved mechanisms by which symbionts can alter their host's behaviour: modulating the biosynthesis of neural peptides and neurotransmitters; modulating the abundance of neurotransmitter receptor proteins, disrupting the fundamental architecture and development of the central nervous system; and finally, manipulation of sex pheromones. All mechanisms, either directly or indirectly, serve to modify their host's neural physiology and function, ultimately resulting in modified host behaviour. Researchers investigating how other less understood microbes alter host behaviour should consider first evaluating these previously discovered mechanisms. Understanding which microbes influence behaviour, and the mechanisms by which these are achieved, will permit further investigation into evolutionary processes such as the extended phenotype, will improve our understanding of how animal behaviour is determined, and finally may even lead to improved human mental health.

An increasing number of human mental illnesses, such as autism, increased anxiety and depression, have been linked to gut flora $[22,60]$. Consequently, one could imagine that future treatments of mental illness may include administration of probiotics that would modify gut flora community structures. Indeed recent clinical trials indicate that for some patients, administration of probiotics is capable of improving mental health [77]. To advance this emerging field of medical research will require experimental approaches that will describe the microbial community of the gut and identify behaviour-modifying species. In addition manipulative experiments that seek to either modify microbial communities or the molecular signals employed by microbes will be critical to the development of therapeutics. As microbiologists and neurobiologists continue to analyse behaviourmodifying microbes in detail, our understanding of what determines animal behaviour will move beyond genetics and environment to include a third and vastly complex component-microbes.

\section{References}

1. Acheson A, Conover JC, Fandl JP, DeChiara TM, Russell M, Thadani A, Squinto SP, Yancopoulos GD, Lindsay RM (1995) A BDNF autocrine loop in adult sensory neurons prevents cell death. Nature 374(6521):450-453. doi:10.1038/374450a0

2. Adamo SA, Webster JP (2013) Neural parasitology: how parasites manipulate host behaviour. J Exp Biol 216(Pt 1):1-2. doi:10. $1242 / \mathrm{jeb} .082511$

3. Anton de Bary H (1869) Die Erscheinung der Symbiose. Revue Internationale des Sciences, Strassburg

4. Backhed F, Ley RE, Sonnenburg JL, Peterson DA, Gordon JI (2005) Host-bacterial mutualism in the human intestine. Science 307(5717):1915-1920. doi:10.1126/science. 1104816

5. Bauermeister J, Ramette A, Dattagupta S (2012) Repeatedly evolved host-specific ectosymbioses between sulfur-oxidizing bacteria and amphipods living in a cave ecosystem. Plos One 7(11):e50254. doi:10.1371/journal.pone.0050254

6. Berdoy M, Webster JP, Macdonald DW (1995) Parasite-altered behaviour: is the effect of Toxoplasma gondii on Rattus norvegicus specific? Parasitology 111(Pt 4):403-409

7. Berdoy M, Webster JP, Macdonald DW (2000) Fatal attraction in rats infected with Toxoplasma gondii. Proc Biol Sci 267(1452):1591-1594. doi:10.1098/rspb.2000.1182

8. Berenreiterova M, Flegr J, Kubena AA, Nemec P (2011) The distribution of Toxoplasma gondii cysts in the brain of a mouse with latent toxoplasmosis: implications for the behavioral manipulation hypothesis. PLoS One 6(12):e28925. doi:10.1371/ journal.pone.0028925

9. Bergami M, Santi S, Formaggio E, Cagnoli C, Verderio C, Blum R, Berninger B, Matteoli M, Canossa M (2008) Uptake and recycling of pro-BDNF for transmitter-induced secretion by cortical astrocytes. J Cell Biol 183(2):213-221. doi:10.1083/jcb. 200806137

10. Biron DG, Marche L, Ponton F, Loxdale HD, Galeotti N, Renault L, Joly C, Thomas F (2005) Behavioural manipulation in a grasshopper harbouring hairworm: a proteomics approach. Proc R Soc B Biol Sci 272(1577):2117-2126. doi:10.1098/rspb.2005.3213

11. Bravo JA, Forsythe P, Chew MV, Escaravage E, Savignac HM, Dinan TG, Bienenstock J, Cryan JF (2011) Ingestion of Lactobacillus strain regulates emotional behavior and central GABA receptor expression in a mouse via the vagus nerve. Proc Natl Acad Sci USA 108(38):16050-16055. doi:10.1073/pnas. 1102999108

12. Brownlie JC, Cass BN, Riegler M, Witsenburg JJ, Iturbe-Ormaetxe I, McGraw EA, O'Neill SL (2009) Evidence for metabolic provisioning by a common invertebrate endosymbiont, Wolbachia pipientis, during periods of nutritional stress. PLoS Pathog 5(4):e1000368. doi:10.1371/journal.ppat.1000368

13. Burand JP, Tan W, Kim W, Nojima S, Roelofs W (2005) Infection with the insect virus $\mathrm{Hz}-2 \mathrm{v}$ alters mating behavior and pheromone production in female Helicoverpa zea moths. J Insect Sci 5:6 
14. Callahan PS (1958) Serial morphology as a technique for determination of reproductive patterns in the corn earworm, Heliothis zae. Ann Entomol Soc Am 51:271-283

15. Caragata EP, Real KM, Zalucki MP, McGraw EA (2011) Wolbachia infection increases recapture rate of field-released Drosophila melanogaster. Symbiosis 54:55-60

16. Carruthers VB, Cotter PA, Kumamoto CA (2007) Microbial pathogenesis: mechanisms of infectious disease. Cell Host Microbe 2(4):214-219. doi:10.1016/j.chom.2007.09.007

17. Champion de Crespigny FE, Pitt TD, Wedell N (2006) Increased male mating rate in Drosophila is associated with Wolbachia infection. J Evol Biol 19(6):1964-1972

18. Creed F, Guthrie E (1987) Psychological factors in the irritable bowel syndrome. Gut 28(10):1307-1318

19. Cryan JF, Kaupmann K (2005) Don't worry 'B' happy!: a role for GABA(B) receptors in anxiety and depression. Trends Pharmacol Sci 26(1):36-43. doi:10.1016/j.tips.2004.11.004

20. Dawkins R (1982) The extended phenotype: the long reach of the gene. Oxford University Press, Oxford

21. Denkers EY, Gazzinelli RT (1998) Regulation and function of T-cell-mediated immunity during Toxoplasma gondii infection. Clin Microbiol Rev 11(4):569-588

22. Desbonnet L, Clarke G, Shanahan F, Dinan TG, Cryan JF (2013) Microbiota is essential for social development in the mouse. Mol Psychiatry. doi: 10.1038/mp.2013.65

23. Dillon RJ, Dillon VM (2004) The gut bacteria of insects: nonpathogenic interactions. Annu Rev Entomol 49:71-92. doi:10. 1146/annurev.ento.49.061802.123416

24. Douglas AE (2010) The symbiotic habit. Princeton University Press, Prinston

25. Douglas AE (2011) Lessons from studying insect symbioses. Cell Host Microbe 10(4):359-367. doi:10.1016/j.chom.2011.09.001

26. El-Husseini AE, Craven SE, Chetkovich DM, Firestein BL, Schnell E, Aoki C, Bredt DS (2000) Dual palmitoylation of PSD-95 mediates its vesiculotubular sorting, postsynaptic targeting, and ion channel clustering. J Cell Biol 148(1):159-172

27. Fisar Z, Hroudova J (2010) Common aspects of neuroplasticity, stress, mood disorders and mitochondrial functions. Act Nerv Super Rediviva 52:1-20

28. Forsythe P, Kunze WA (2012) Voices from within: gut microbes and the CNS. Cell Mol Life Sci 70(1):55-69. doi:10.1007/ s00018-012-1028-z

29. Gaskell EA, Smith JE, Pinney JW, Westhead DR, McConkey GA (2009) A unique dual activity amino acid hydroxylase in Toxoplasma gondii. PLoS One 4(3):e4801. doi:10.1371/journal.pone. 0004801

30. Godde JS (2012) Breaking through a phylogenetic impasse: a pair of associated archaea may have played host in the endosymbiotic origin of eukaryotes. Cell Biosci 2(1):29

31. Guarner F, Malagelada JR (2003) Gut flora in health and disease. Lancet 361(9356):512-519. doi:10.1016/S0140-6736(03)12489-0

32. Guillery RW (2005) Observations of synaptic structures: origins of the neuron doctrine and its current status. Philos Trans R Soc Lond B Biol Sci 360(1458):1281-1307. doi:10.1098/rstb.2003. 1459

33. Hamm J, Carpenter J, Styer E (1996) Oviposition day effect on incidence of agonadal progeny of Helicoverpa zea. Ann Entomol Soc Am 56:535-556

34. Hanelt B, Janovy J Jr (1999) The life cycle of a horsehair worm, Gordius robustus (Nematomorpha: Gordioidea). J Parasitol 85(1):139-141

35. Hay J, Aitken PP, Arnott MA (1985) The influence of congenital Toxoplasma infection on the spontaneous running activity of mice. Zeitschrift fur Parasitenkunde 71(4):459-462

36. Heijtz DR, Wang S, Anuar F, Qian Y, Bjorkholm B, Samuelsson A, Hibberd ML, Forssberg H, Pettersson S (2011) Normal gut microbiota modulates brain development and behavior. Proc Natl Acad Sci USA 108(7):3047-3052. doi:10.1073/pnas.1010529108 37. Hermes G, Ajioka JW, Kelly KA, Mui E, Roberts F, Kasza K, Mayr T, Kirisits MJ, Wollmann R, Ferguson DJ, Roberts CW, Hwang JH, Trendler T, Kennan RP, Suzuki Y, Reardon C, Hickey WF, Chen L, McLeod R (2008) Neurological and behavioral abnormalities, ventricular dilatation, altered cellular functions, inflammation, and neuronal injury in brains of mice due to common, persistent, parasitic infection. J Neuroinflamm 5:48. doi:10.1186/1742-2094-5-48

38. Hilgenboecker K, Hammerstein P, Schlattmann P, Telchow A, Werren JH (2008) How many species are infected with Wolbachia? - a statistical analysis of current data. FEMS Microbiol Lett 281(2):215-220

39. Hodkova H, Kolbekova P, Skallova A, Lindova J, Flegr J (2007) Higher perceived dominance in Toxoplasma infected men-a new evidence for role of increased level of testosterone in toxoplasmosis-associated changes in human behavior. Neuro Endocrinol Lett 28(2):110-114

40. Hogan M (2011) Commensalism environmental information coalition. National Council for Science and the Environment, Washington, DC

41. Hooper L (2010) Immune adaptations that maintain homeostasis with the intestinal microbiota. Nat Rev Immunol 10(3):159-169

42. Hrdá S, Votýpka J, Kodym P, Flegr J (2000) Transient nature of Toxoplasma gondii-induced behavioral changes in mice. J Parasitol 86(4):657-663

43. Huang E, Reichardt L (2001) Neurotrophins: roles in neuronal development and function. Annu Rev Neurosci 24:677-736

44. Hunter P (2009) How smart is smart? Is human intelligence still evolving? EMBO Rep 10(11):1198-1201. doi:10.1038/embor. 2009.234

45. Jeyaprakash A, Hoy MA (2000) Long PCR improves Wolbachia DNA amplification: wsp sequences found in $76 \%$ of sixty-three arthropod species. Insect Mol Biol 9(4):393-405

46. Kalidas S, Smith DP (2002) Novel genomic cDNA hybrids produce effective RNA interference in adult Drosophila. Neuron 33(2):177-184 S0896627302005603

47. Kaufman S (1995) Tyrosine hydroxylase. Adv Enzymol Relat Areas Mol Biol 70:103-220

48. Kingan TG, Bodnar WM, Raina AK, Shabanowitz J, Hunt DF (1995) The loss of female sex-pheromone after mating in the corn-earworm moth Helicoverpa-Zea-identification of a male pheromonostatic peptide. Proc Natl Acad Sci USA 92(11): 5082-5086. doi:10.1073/pnas.92.11.5082

49. Kingan TG, Thomaslaemont PA, Raina AK (1993) Male accessorygland factors elicit change from virgin to mated behavior in the female corn-earworm moth Helicoverpa zea. J Exp Biol 183:61-76

50. Lafferty K, Morris K (1996) Altered behavior of parasitized killifish increases susceptibility to predation by bird final hosts. Ecology 77(5):1390-1397

51. Lafferty KD, Shaw JC (2013) Comparing mechanisms of host manipulation across host and parasite taxa. J Exp Biol 216(Pt 1): 56-66. doi:10.1242/jeb.073668

52. Lemaitre B, Hoffmann J (2007) The host defense of Drosophila melanogaster. Annu Rev Immunol 25:697-743. doi:10.1146/ annurev.immunol.25.022106.141615

53. Leulier F, Royet J (2009) Maintaining immune homeostasis in fly gut. Nat Immunol 10(9):936-938. doi:10.1038/ni0909-936

54. Libersat F, Delago A, Gal R (2009) Manipulation of host behavior by parasitic insects and insect parasites. Annu Rev Entomol 54:189-207. doi:10.1146/annurev.ento.54.110807.090556

55. Matthews DM, Jenks SM (2013) Ingestion of Mycobacterium vaccae decreases anxiety-related behavior and improves learning in mice. Behav Process 96:27-35. doi:10.1016/j.beproc. 2013.02.007 
56. McDonald S, Saad A, James C (2011) Social dysdecorum following severe traumatic brain injury: loss of implicit social knowledge or loss of control? J Clin Exp Neuropsychol. doi:10. 1080/13803395.2011.553586

57. McGue M, Bouchard TJ Jr (1998) Genetic and environmental influences on human behavioral differences. Annu Rev Neurosci 21:1-24. doi:10.1146/annurev.neuro.21.1.1

58. Montoya JG, Liesenfeld O (2004) Toxoplasmosis. Lancet 363(9425):1965-1976. doi:10.1016/S0140-6736(04)16412-X

59. Neufeld KM, Kang N, Bienenstock J, Foster JA (2011) Reduced anxiety-like behavior and central neurochemical change in germfree mice. Neurogastroenterol Motil 23(3):255-264. doi:10.1111/ j.1365-2982.2010.01620.x e119

60. Parracho HM, Bingham MO, Gibson GR, McCartney AL (2005) Differences between the gut microflora of children with autistic spectrum disorders and that of healthy children. J Med Microbiol 54(Pt 10):987-991. doi:10.1099/jmm.0.46101-0

61. Peng Y, Nielsen JE, Cunningham JP, McGraw EA (2008) Wolbachia infection alters olfactory-cued locomotion in Drosophila spp. Appl Environ Microbiol 74(13):3943-3948. doi:10.1128/ AEM.02607-07

62. Peng Y, Wang Y (2009) Infection of Wolbachia may improve the olfactory response of Drosophila. Chin Sci Bull 54(8):13691375. doi:10.1007/s11434-009-0183-6

63. Qin J, Li R, Raes J, Arumugam M, Burgdorf KS, Manichanh C, Nielsen T, Pons N, Levenez F, Yamada T, Mende DR, Li J, Xu J, Li S, Li D, Cao J, Wang B, Liang H, Zheng H, Xie Y, Tap J, Lepage P, Bertalan M, Batto JM, Hansen T, Le Paslier D, Linneberg A, Nielsen HB, Pelletier E, Renault P, SicheritzPonten T, Turner K, Zhu H, Yu C, Li S, Jian M, Zhou Y, Li Y, Zhang $\mathrm{X}$, Li S, Qin N, Yang H, Wang J, Brunak S, Dore J, Guarner F, Kristiansen K, Pedersen O, Parkhill J, Weissenbach J, Meta HITC, Bork P, Ehrlich SD, Wang J (2010) A human gut microbial gene catalogue established by metagenomic sequencing. Nature 464(7285):59-65. doi:10.1038/nature08821

64. Raina AK, Adams JR (1995) Gonad-specific virus of corn earworm. Nature 374:770

65. Raina AK, Jaffe H, Kempe TG, Blacher R, Fales H, Riley C, Klun J, Ridgway R, Hayes D (1989) Identification of a neuropeptide hormone that regulates sex pheromone production in female moths. Science 244:796-798

66. Sanchez MI, Ponton F, Misse D, Hughes DP, Thomas F (2008) Hairworm response to notonectid attacks. Anim Behav 75:823-826. doi:10.1016/j.anbehav.2007.07.002

67. Sansonetti PJ (2004) War and peace at mucosal surfaces. Nat Rev Immunol 4:953-964

68. Sekirov I, Finlay BB (2009) The role of the intestinal microbiota in enteric infection. J Physiol 587(Pt 17):4159-4167. doi:10. 1113/jphysiol.2009.172742

69. Sharon G, Segal D, Ringo JM, Hefetz A, Zilber-Rosenberg I, Rosenberg E (2010) Commensal bacteria play a role in mating preference of Drosophila melanogaster. Proc Natl Acad Sci USA 107(46):20051-20056. doi:10.1073/pnas.1009906107

70. Sharon G, Segal D, Zilber-Rosenberg I, Rosenberg E (2011) Symbiotic bacteria are responsible for diet-induced mating preference in Drosophila melanogaster, providing support for the hologenome concept of evolution. Gut Microbes 2(3):190-192

71. Shaw JC, Hechinger RF, Lafferty KD, Kuris AM (2010) Ecology of the brain trematode Euhaplorchis californiensis and its host, the California killifish (Fundulus parvipinnis). J Parasitol 96(3):482-490. doi:10.1645/GE-2188.1
72. Shaw JC, Overli O (2012) Brain-encysting trematodes and altered monoamine activity in naturally infected killifish Fundulus parvipinnis. J Fish Biol 81(7):2213-2222. doi:10.1111/j.1095-8649. 2012.03439.x

73. Skallova A, Kodym P, Frynta D, Flegr J (2006) The role of dopamine in Toxoplasma-induced behavioural alterations in mice: an ethological and ethopharmacological study. Parasitology 133(Pt 5):525-535. doi:10.1017/S0031182006000886

74. Stibbs HH (1985) Changes in brain concentrations of catecholamines and indoleamines in Toxoplasma gondii infected mice. Ann Trop Med Parasitol 79(2):153-157

75. Summers $\mathrm{CH}$, Winberg S (2006) Interactions between the neural regulation of stress and aggression. J Exp Biol 209(Pt 23):4581-4589. doi:10.1242/jeb.02565

76. Thomas F, Schmidt-Rhaesa A, Martin G, Manu C, Durand P, Renaud F (2002) Do hairworms (Nematomorpha) manipulate the water seeking behaviour of their terrestrial hosts? J Evol Biol 15(3):356-361. doi:10.1046/j.1420-9101.2002.00410.x

77. Tillisch K, Labus J, Kilpatrick L, Jiang Z, Stains J, Ebrat B, Guyonnet D, Legrain-Raspaud S, Trotin B, Naliboff B, Mayer EA (2013) Consumption of fermented milk product with probiotic modulates brain activity. Gastroenterology 144(7): 1394-1401. doi:10.1053/j.gastro.2013.02.043 e1394

78. Torda A (2001) Toxoplasmosis. Are cats really the source? Aust Fam Physician 30(8):743-747

79. Vosshall LB, Wong AM, Axel R (2000) An olfactory sensory map in the fly brain. Cell 102(2):147-159 S0092-8674(00)00021-0

80. Vyas A, Kim SK, Giacomini N, Boothroyd JC, Sapolsky RM (2007) Behavioral changes induced by Toxoplasma infection of rodents are highly specific to aversion of cat odors. Proc Natl Acad Sci USA 104(15):6442-6447. doi:10.1073/pnas.0608310104

81. Walker JR, Ediger JP, Graff LA, Greenfeld JM, Clara I, Lix L, Rawsthorne P, Miller N, Rogala L, McPhail CM, Bernstein CN (2008) The Manitoba IBD cohort study: a population-based study of the prevalence of lifetime and 12-month anxiety and mood disorders. Am J Gastroenterol 103(8):1989-1997. doi:10.1111/j. 1572-0241.2008.01980.x

82. Webster JP (1994) Prevalence and transmission of Toxoplasma gondii in wild brown rats, Rattus norvegicus. Parasitology 108(Pt 4): 407-411

83. Webster JP, Brunton CF, MacDonald DW (1994) Effect of Toxoplasma gondii upon neophobic behaviour in wild brown rats, Rattus norvegicus. Parasitology 109(Pt 1):37-43

84. Webster JP, Lamberton PH, Donnelly CA, Torrey EF (2006) Parasites as causative agents of human affective disorders? The impact of anti-psychotic, mood-stabilizer and anti-parasite medication on Toxoplasma gondii's ability to alter host behaviour. Proc Biol Sci 273(1589):1023-1030. doi:10.1098/rspb.2005.3413

85. Werren JH, Windsor D, Guo L (1995) Distribution of Wolbachia among neotropical arthropods. Proc R Soc Lond Biol Sci Series B 262(1364):197-204

86. Witting PA (1979) Learning capacity and memory of normal and Toxoplasma-infected laboratory rats and mice. Zeitschrift fur Parasitenkunde 61(1):29-51

87. Wood JD (2007) Neuropathophysiology of functional gastrointestinal disorders. World J Gastroenterol 13(9):1313-1332

88. Zug R, Hammerstein P (2012) Still a host of hosts for Wolbachia: analysis of recent data suggests that $40 \%$ of terrestrial arthropod species are infected. PLoS One 7(6):e38544. doi:10.1371/journal. pone. 0038544 